\title{
A tese de Williams e o Antigo Sistema Colonial: notas sobre um debate clássico*
}

\author{
Williams's thesis and the Old Colonial System: notes on a classical debate
}

\author{
Carlos Leonardo Kelmer Mathias \\ clkmathias@uol.com.br \\ Professor adjunto \\ Universidade Federal Rural do Rio de Janeiro \\ Rua Francisco Couri, n. 31 (sobrado) - Bom Clima \\ 6046-450 - Juiz de Fora - MG \\ Brasil
}

\section{Resumo}

O presente artigo examina a influência da chamada tese de Williams no clássico livro de Fernando Novais, Portugal e Brasil na crise do Antigo Sistema Colonial. Mais de perto, o texto analisa os principais argumentos do trabalho de Eric Williams Capitalismo e escravidão à luz da historiografia acerca do tema e os correlacionam com algumas das noções norteadoras do estudo de Novais. Em linhas gerais, os pontos mais relevantes da tese de Williams consistem no delineamento da contribuição das Índias Ocidentais britânicas para o enriquecimento inglês e para a Revolução Industrial. Nesse sentido, Williams trouxe à baila o debate acerca da importância do tráfico de escravos e da escravidão nesse processo. Inserido no comércio triangular Inglaterra-África-Caribe, o sistema escravista teria concorrido diretamente para o acúmulo de riquezas na pátria mãe. Quando o sistema se mostrou inoportuno para os rumos naturais do capitalismo, iniciaram-se as discussões abolicionistas. O artigo situa o debate em questão e mapeia os ecos de Capitalismo e escravidão no livro base de Fernando Novais. O texto termina por concluir que, no nível da historiografia brasileira, malgrado os recentes avanços, muito ainda há por ser dito acerca desse campo de estudos.

\section{Palavras-chave}

Historiografia comparada; Historiografia brasileira; Escravidão.

\section{Abstract}

This article examines the influence of Williams' thesis on the classic book by Fernando Novais, Portugal e Brasil na crise do Antigo Sistema Colonial. More closely, the paper analyzes the main arguments of the work of Eric Williams (Capitalism and Slavery) in the context of the historiography on the subject, and correlates these arguments with the major concepts of Fernando Novais' study. In general, the most relevant point of Williams' thesis is to emphasize the contribution of the British West Indies both for the enrichment of England and for financing the industrial revolution. In this sense, Williams has brought out the debate on the importance of the slave trade and of slavery in this process. Inserted in the triangular trade England-Africa-Caribbean, the slave system is reputed to have contributed directly to the accumulation of wealth in the mother country. When the system became a problem for the natural course of capitalism, the abolitionist discussions were initiated. The article analyzes this debate and the influence of Capitalism and Slavery in Fernando Novais' book, and it concludes that at the level of Brazilian historiography, despite recent advances, much remains to be said about this field of study.

\section{Keywords}

Historiography compared; Brazilian historiography; Slavery.

\author{
Enviado em: 6/5/2012
}

Aprovado em: 11/6/2012

\footnotetext{
* Esta pesquisa é financiada pelo CNPq e pela FAPERJ.
} 


\section{Capitalismo e escravidão, a tese de Williams}

Publicado originalmente em 1944, Capitalismo e escravidão de Eric Williams logo se tornou um dos livros referência nos estudos acerca do papel dos escravos africanos no processo de enriquecimento do império britânico da época moderna. Nas palavras do autor, trata-se de um "estudo do papel da escravidão negra e do tráfico de escravos no fornecimento do capital que financiou a Revolução Industrial e da maturidade do capitalismo industrial em destruir o sistema escravista" (WILLIAMS 1994, p. IX). Segundo Colin Palmer - autor da introdução da edição em inglês de 1994 -, o trabalho de Williams teria inaugurado uma nova fase nos estudos concernentes à relação entre o poder colonial e suas colônias, trazendo à baila o debate sobre a importância da escravidão africana e do tráfico de escravos para a economia inglesa da época. Dessa forma, sua obra contribuiu para mudar a "visão tradicional de que as colônias eram mais recipientes da benevolência metropolitana e menos agentes principais na construção da prosperidade do poder imperial" (PALMER; WILLIAMS 1994, p. XXI).

No Brasil, Capitalismo e escravidão foi primeiro publicado em 1975 pela editora Americana. Passados 37 anos, o livro ganhou nova edição, dessa feita pela editora Companhia das Letras e prefaciado por Rafael de Bivar Marquese. Em linhas gerais, Marquese aborda o caminho percorrido por Williams desde seu ingresso na universidade de Oxford $^{1}$ até a publicação de seu trabalho, ${ }^{2}$ pontua os primeiros textos brasileiros influenciados pela abordagem de Williams e realiza uma exposição acerca, notadamente, das críticas realizadas por Ciro Cardoso a Capitalismo e escravidão (MARQUESE; WILLIAMS 2012, p. 9-23). Nesses termos, embora sirva ao propósito para o qual fora escrito, o prefácio de Marquese não aborda o debate internacional originado com a publicação de Capitalismo e escravidão. Assim, salvo aqueles mais versados na matéria, o leitor da obra resta alheio a essa importante discussão que em muito favorece na compreensão do tema abordado. Rafael Marquese não tece maiores considerações sobre a influência de Eric Williams no clássico livro de Fernando Novais Portugal e Brasil na crise do Antigo Sistema Colonial, assunto do presente artigo. Na medida em que a obra de Novais é uma das referências para o pesquisador do Brasil Colônia, estabelecer as influências de Williams em seu texto à luz do debate internacional da época ${ }^{3}$ fornece outras ferramentas para a compreensão de Capitalismo e escravidão além de situar os estudiosos que dialogam com o livro de Novais. Em essência, esse é o objetivo do corrente artigo.

Voltando ao livro em si, Williams argumenta que a riqueza da Europa se deveu à exploração do trabalho africano através do tráfico de escravos e da

\footnotetext{
${ }^{1}$ Foi onde Williams cursou o doutorado, cujo produto final é o livro ora discutido.

${ }^{2}$ A propósito de uma discussão mais aprofundada sobre o tema ver ANSTEY 1968; HENRY 1997; BECKLES 1997, além da introdução de Colin Palmer anteriormente citada.

${ }^{3} \mathrm{Na}$ medida em que o artigo trata do debate em questão, a maior parte da bibliografia utilizada foi produzida entre as décadas de 1950 e 1980, malgrado alguns textos fujam a tal recorte cronológico. O artigo não aprofunda na discussão de temas aqui apenas tangenciados como, por exemplo, o Tratado de Methuen. Isso ocorre por que, além de não ser o objetivo de o artigo estudar o assunto (e sim estabelecer as influências de Williams em Novais), tal tema mereceria, por si mesmo, um artigo para ser tratado de forma adequada.
} 
escravidão caribenha. Em sua compreensão, a produção das Índias Ocidentais britânicas atuou sobremaneira na formação do capital inglês, lançando as fundações para a Revolução Industrial, através do comércio triangular Inglaterra-África-Caribe. Com que então as ilhas caribenhas passaram a desempenhar um papel central no sistema econômico atlântico. Por fim, e aqui repousa uma das principais contribuições do livro, para Williams a abolição do tráfico, assim como a posterior emancipação dos escravos, se deveu não tanto à atuação dos abolicionistas, mas ao arrefecimento da economia açucareira da região no final do século XVIII. Com a independência dos Estados Unidos e a publicação de A riqueza das nações, ${ }^{4}$ teve vez uma forte crença de que o trabalho escravo era ineficiente, não lucrativo e um atraso ao desenvolvimento econômico. Dessa forma, a abolição da escravidão encerraria um dos principais entraves no progresso econômico ocidental. ${ }^{5}$

Richard Sheridan assegura que fatores de ordem econômica estavam não somente por detrás do movimento abolicionista, mas também responderam pela própria adoção da mão de obra africana no Caribe. Em detalhe, à medida que o trabalho camponês livre foi se tornando mais oneroso, os planters orientaram seus esforços para a escravidão negra. Em seu entendimento, embora o capital inicial para a aquisição de africanos fosse superior aos salários pagos aos camponeses, os cativos possuíam a prerrogativa de se autorreproduzirem, eram menos custosos para alimentar e vestir, possuíam superioridade física e maior resistência às doenças quando em comparação com os brancos e os índios (SHERIDAN 1972, p. 16). ${ }^{6}$ Tais fatores concorreram diretamente para que os escravos estivessem aptos a suportar o ônus da produção em um contexto mercantilista profundamente marcado pela busca de riqueza e lucro. Segundo Robin Blackburn, um dos fatores responsáveis por acelerar o ritmo da industrialização capitalista inglesa consistiu precisamente na "superexploração dos escravos nas Américas". Conforme o autor, "as trocas com as plantations escravistas ajudaram o capitalismo britânico a avançar para o industrialismo e a hegemonia global à frente de seus rivais" (BLACKBURN 2003, p. 693).

Todavia, Capitalismo e escravidão também suscitou vários questionamentos e críticas. Joseph Inikori sugere que Williams não obteve sucesso na comprovação de sua hipótese segundo a qual o sistema escravista teria contribuído de forma decisiva para a Revolução Industrial. Conforme o autor, isso se deveu tanto ao fato de não

\footnotetext{
${ }^{4}$ Vale sublinhar que para Adam Smith as colônias britânicas consistiam "um projeto que tem custado, que continua a custar e que, continuando da mesma maneira como tem sido até agora, deverá custar uma imensa despesa, sem que pareça dar qualquer lucro" (SMITH 2010, p. 420).

5 Em tempo, Selwyn Carrington considera Capitalism and slavery mais do que um trabalho acadêmico, um instrumento desafiador do colonialismo coevo à sua publicação e do duradouro controle do Caribe pelos poderes imperiais. À vista disso, muitos afrodescendentes enxergaram o livro de Williams como ferramenta que os possibilitavam se orgulharem de seus antepassados, pois passaram a ser vistos como agentes do processo de engrandecimento do império inglês - malgrado as condições de exploração às quais haviam sido submetidos (CARRINGTON 2003, p. 304-305). Não obstante a tímida repercussão da obra em função da $2^{\text {a }}$ Guerra Mundial, ao término do conflito o livro alcançou a comunidade acadêmica. Entre os intelectuais africanos, Capitalism and slavery foi celebrado como uma declaração contrária ao imperialismo britânico. Nota-se que muito dessa recepção foi caudatária do contexto avesso ao colonialismo que vigorou na segunda metade do século passado (ANSTEY 1968, p. 307-308).

6 Tal argumentação pode ser previamente encontrada em Casa-grande e senzala, cuja primeira edição data de 1933.
} 
haver, na época da elaboração do livro, instrumentos metodológicos e empíricos disponíveis para o intento, como por não ser aquele o foco principal de Williams. Para Inikori, o principal propósito do livro seria estudar a relação entre a abolição e a Revolução Industrial, leia-se capitalismo industrial (INIKORI 2002, p. 3-7). Por seu turno, D. A. Farnie, seguindo de perto a linha smithiana, aponta que as plantations caribenhas inglesas dependiam do poder metropolitano para obtenção de mão de obra, capital, mercado, manufatura e proteção naval. Logo, a produção local açucareira não possuía condições de financiar sequer uma aristocracia fundiária, quanto mais a industrialização inglesa (FARNIE 1962, p. 206-210). ${ }^{7}$

Para David Richardson, a despeito de algumas argumentações terem demonstrado que o tráfico de escravos e seu papel no financiamento da industrialização foram menos representativos do que Williams alegou, Capitalismo e escravidão continua a ter grande influência na historiografia que advoga em prol da importância do comércio triangular (notadamente o tráfico) no processo de gestão/financiamento da Revolução Industrial. Afirma que tal influência é devedora do fato de Williams ter apresentado seus argumentos de maneira muito ampla e genérica, não indicando claramente se ele estava a se referir aos lucros do tráfico de escravos isoladamente ou à combinação quer do comércio colonial triangular, quer do bilateral. De resto, o autor não determinou, em termos geográficos e cronológicos, as ligações que ele acreditava terem existido entre tráfico de escravos, comércio agrícola e desenvolvimento industrial (RICHARDSON 1987, p. 104).

De forma geral, e no que concerne às proposições de Williams, discute-se a importância e o papel do tráfico e da escravidão no processo de industrialização britânica, as origens da implantação do escravismo nas Índias Ocidentais inglesas, o porquê de sua abolição, o funcionamento do chamado comércio triangular etc. No Brasil, o trabalho que mais se valeu das ideias apresentadas pelo clássico Capitalismo e escravidão foi o hoje também clássico Portugal e Brasil na crise do Antigo Sistema Colonial de Fernando Antônio Novais.

\section{A tese de Williams e o Antigo Sistema Colonial}

Consoante Eric Williams, o comércio triangular forneceu um estímulo triplo para a Revolução Industrial. Primeiro, os escravos eram permutados na África por produtos manufaturados ingleses, o que contribuía para fomentar a produção doméstica britânica. Posteriormente, uma vez tendo cruzado Atlântico, os negros eram deslocados para as plantations, onde produziam açúcar, algodão, anil e outros produtos tropicais que serviam de matéria-prima ou estimulavam a criação de novas atividades industriais na Inglaterra. Nesse cenário, a manutenção do sistema estimulava um mercado ultramarino para produtos industrializados ingleses. Essa operação era extremamente lucrativa para os negociantes e industriais nela atuantes (WILLIAMS 1994, p. 51-52).

\footnotetext{
7 Para uma visão contrária cf. T. G. Burnard, que defende ter sido a Jamaica, a mais rica colônia britânica na América por volta de 1775, perfeitamente capaz de gerar riqueza e, em certa medida, sustentar a si mesma. Conforme Burnard, a "Jamaica era rica por que os brancos lucravam com os $92 \%$ da população que eles tinham como propriedade" (BURNARD 2001, p. 507-508).
} 
Porém, todo esse arcabouço somente atingiria sua máxima eficiência mediante o emprego de uma política econômica garantidora da primazia metropolitana sobre o mercado colonial. Noutras palavras, tratou-se da implantação do sistema mercantilista de exclusivismo comercial. Em linhas gerais, as colônias se viam obrigadas a remeter seus produtos somente para a Inglaterra e por meio de seus navios. Podiam apenas adquirir produtos de comerciantes ingleses ou por eles reexportados. Segundo Williams, "assim, como uma criança obediente que trabalhava para a maior glória de seus pais, elas [as colônias] eram reduzidas a um estado de vassalagem permanente e confinadas somente à exploração de seus recursos agrícolas". Nada poderia ser manufaturado em território americano e/ou caribenho. Em contrapartida, "a Inglaterra fez apenas uma concessão - aos produtos coloniais foi dado um monopólio do mercado doméstico" (WILLIAMS 1994, p. 56).

Tal argumento aponta a intricada correlação entre tráfico de escravos, mão de obra africana, exclusivo comercial, mercantilismo, acumulação e Revolução Industrial. Esses pensamentos marcaram a proposta central de Novais, para quem o mercantilismo instituiu a montagem do sistema de acumulação cuja resultante foi a Revolução Industrial, donde era o "sistema colonial mercantilista sua peça fundamental, a principal alavanca na gestação do capitalismo moderno [...]; a exploração colonial foi elemento decisivo na criação dos pré-requisitos do capitalismo industrial" (NOVAIS 1995, p. 69-70). Ademais, o chamado Antigo Sistema Colonial do mercantilismo era devedor do exclusivo metropolitano. No 194 que toca ao autor:

\begin{abstract}
Reservando-se a exclusividade do comércio com o Ultramar, as metrópoles europeias na realidade organizavam um quadro institucional de relações tendentes a promover necessariamente um estímulo à acumulação primitiva de capital na economia metropolitana a expensas das economias periféricas coloniais. O chamado 'monopólio colonial', ou mais corretamente e usando um termo da própria época, o regime do 'exclusivo' metropolitano constituía-se pois no mecanismo por excelência do sistema, através do qual se processava o ajustamento da expansão colonizadora aos processos da economia e da sociedade europeias em transição para o capitalismo integral (NOVAIS 1995, p. 72, grifos no original). ${ }^{8}$
\end{abstract}

Em 1929, Earl Hamilton defendeu que durante os séculos XVI e XVII o ouro e a prata produzidos em território americano, assim como o mercado oferecido pelo Estado da Índia, teriam exercido sua maior influência sobre o progresso do capitalismo, ${ }^{9}$ notadamente na Inglaterra, na França e nos Países Baixos. Conforme o autor, tal progresso teria, de fato, preparado o caminho para a Revolução Industrial. O progresso em questão seria fruto de quatro pontos, a saber: a) a introdução de novos produtos agrícolas provenientes da América e de novas mercadorias oriundas da Ásia (especiarias e artigos de luxo) ajudou a

\footnotetext{
${ }^{8}$ Recentemente, André Villela questionou a proposta do Antigo Sistema Colonial de que o exclusivo comercial geraria considerável excedente financeiro para a metrópole que, em última instância, financiaria a Revolução Industrial. Para o autor, isso não ocorreu. Cf. VILLELA 2011, p. 4-29.

9 Para esse período, Hamilton chama de capitalismo o "sistema no qual uma riqueza outra que não a terra é usada para o definido propósito de assegurar uma renda" (HAMILTON 1929, p. 339).
} 
estimular as atividades industriais na Europa e a gerar meios de pagar por tais produtos e mercadorias; b) a emigração diminuiu a pressão populacional na Europa, contribuindo para suscitar um excedente alimentício; c) a abertura de mercados ultramarinos e a disponibilidade de matérias-primas desempenharam papel fundamental na transferência do controle da atividade manufatureira e do comércio das guildas para os capitalistas; d) e esse é o fator mais decisivo, o influxo de metais preciosos ofertou um aumento de capital disponível na Europa. Segundo Hamilton, os enormes lucros aferidos a partir da concatenação desses fatores contribuíram para o progresso do capitalismo por intermédio do fomento da Revolução Industrial (HAMILTON 1929, p. 338-357).

À semelhança da tese de Williams, Hamilton observou a importância do ultramar no financiamento da Revolução Industrial inglesa, destacando não apenas o comércio atlântico, mas também o exclusivo metropolitano no acesso, por exemplo, à prata da América espanhola e ao ouro dos domínios portugueses. A principal diferença entre os autores repousa no fato de que Hamilton não teceu maiores considerações acerca da contribuição do tráfico de escravos e da mão de obra africana no progresso do capitalismo em geral, e da Revolução Industrial em particular. Fernando Novais promoveu a junção de ambos os fatores, na medida em que o autor concatena o exclusivo metropolitano e o emprego da escravidão como os principais fatores contribuintes da acumulação primitiva de capital. Nas palavras do autor:

O exclusivo metropolitano do comércio colonial consiste em suma na reserva do mercado das colônias para a metrópole, isto é, para a burguesia comercial metropolitana. Este o mecanismo fundamental gerador de lucros excedentes, lucros coloniais; através dele, a economia central metropolitana incorporava o sobreproduto das economias coloniais ancilares (NOVAIS 1995, p. 88-89, grifos no original).

Consoante Novais, o objetivo do emprego do escravismo consistia em dar a forma necessária à produção colonial de modo que a tornasse capaz de viabilizar estímulos à acumulação capitalista burguesa (NOVAIS 1995, p. 9798). Segundo o autor:

Nas condições históricas em que se processa a colonização da América, a implantação de formas compulsórias de trabalho decorria fundamentalmente da necessária adequação da empresa colonizadora aos mecanismos do Antigo Sistema Colonial tendente a promover a primitiva acumulação capitalista na economia europeia (NOVAIS 1995, p. 102).

Ainda acerca da temática do exclusivo metropolitano, Fisher ressaltou, em 1963, que a partir da última década do Seiscentos, e em função das descobertas auríferas na região de Minas Gerais, as exportações inglesas para Portugal apresentaram um considerável crescimento. Nessa esteira, Portugal se tornou um dos ramos mais importantes do comércio externo inglês, revelando uma balança comercial extremamente favorável à Inglaterra. Fatores como o comércio de bacalhau, o uso que os portugueses faziam dos navios britânicos 
no trato ultramarino, o crédito ofertado por mercadores britânicos aos lusos para o comércio de tecidos, o estreito relacionamento entre ingleses e membros diretores de companhias de comércio portuguesas contribuíram para que a balança de pagamentos entre os dois países pendesse positivamente para a Inglaterra. Toda essa situação era devedora do fato de a Inglaterra ser a nação mais favorecida no comércio com Portugal e suas colônias, notadamente o Brasil. Conforme Fisher, as relações mercantis firmadas entre Inglaterra e Brasil excediam o combinado das trocas comercias da Inglaterra com a França e os Países Baixos. Nesse sentido, os tratados comerciais anglo-lusos de 1642, 1654, 1661 e 1703 "que regularam seu mútuo comércio tiveram muito efeito nessa conexão" (FISHER 1963, p. 220-229). ${ }^{10}$

Segundo Fernando Novais, o tratado de Methuen serviu a dois propósitos. De um lado, garantiu ao trono português uma posição confortável frente ao beligerante contexto europeu no século XVIII. Por outro, postando-se sob o abrigo da potência britânica, os lusos uniram seus mercados americanos aos ingleses. Tal entendimento é formulado nas passagens a seguir: "a diplomacia portuguesa tentou, é certo, manter-se à margem [...], mas acabou por ceder aos imperativos da situação, apertando-se ainda mais os liames com a Inglaterra. Os tratos de Methuen consolidaram afinal esta situação". Em outro ponto se lê: "o segundo tratado de Methuen, abrindo o mercado português aos tecidos ingleses criava também a possibilidade de a indústria inglesa, através de Portugal, alcançar o mercado da América portuguesa" (NOVAIS 1995, p. 24; 43).

196 Conforme avançado, Eric Williams advoga em prol da forte contribuição do comércio triangular no enriquecimento britânico ao longo do século XVIII; donde a grande importância da escravidão africana no processo. Tal assertiva influenciou consideravelmente Fernando Novais. Isso pode ser percebido quando o autor afirma que

produzir para o mercado europeu nos quadros do comércio colonial tendente a promover a acumulação primitiva de capital nas economias europeias exigia formas compulsórias de trabalho, pois do contrário, ou não se produziria para o mercado europeu (os colonos povoadores desenvolveriam uma economia voltada par o próprio consumo), ou se se imaginasse uma produção exportadora por empresários que assalariassem trabalho, os custos da produção seriam tais que impediriam a exploração colonial, e pois a função da colonização no desenvolvimento do capitalismo europeu (NOVAIS 1995, p. 102-103).

Desnecessário dizer que o autor percebe o Antigo Sistema Colonial como "uma peça da acumulação primitiva de capitais nos quadros do desenvolvimento do capitalismo mercantil europeu" (NOVAIS 1995, p. 92). Malgrado as críticas de Ciro Cardoso à tese de Williams, ${ }^{11}$ autores ainda corroboram a essência das ideias acima alocadas. Para José Arruda:

\footnotetext{
10 Para Jacob Price, muito do sucesso dos mercadores britânicos no comércio ultramarino se deveu à sua exclusividade no acesso a determinados mercados (PRICE 1989, p. 274).

${ }^{11}$ Cf., por exemplo, CARDOSO 1980, p. 109-132; 2004, p. 7-29 e o prefácio de Rafael Marquese citado anteriormente.
} 
É inegável, portanto, a decisiva importância do impacto do mercado mundial e, sobretudo, colonial, na transformação da estrutura técnica da produção industrial inglesa, até então assentada no binômio ferramenta/ energia humana. Isto demonstra que o mundo colonial cumpriu um papel, desempenhando funções precípuas de elo alimentador do processo de acumulação primitiva de capitais, promovendo a transferência de riquezas das colônias para as metrópoles que se digladiavam em torno da apropriação do excedente colonial (ARRUDA 2002, p. 220).

Noutro trabalho, o autor novamente demonstra sua concordância com a perspectiva de exclusivo comercial:

A função precípua da colônia era, portanto, a de acelerar a acumulação primitiva de capitais, produzir excedentes por meio da comercialização dos produtos coloniais nos mercados europeus, lucros estes que beneficiaram diretamente a burguesia mercantil do Reino e a elite aristocrática, incrustada no aparelho de Estrado. Eram lucros de monopólio. Não quaisquer lucros. Expressavam a exclusividade da compra dos produtos coloniais a preços rebaixados e a certeza de altos lucros na revenda. $\mathrm{O}$ abastecimento das necessidades coloniais com produtos produzidos na metrópole ou adquiridos nos mercados continentais, igualmente garantidores de vantagens excepcionais, completavam o circuito (ARRUDA 2000, p. 246).

Recentemente, desenvolvendo a noção de "capital escravista-mercantil" Iraci Costa e Julio Pires defenderam a importância do ultramar, por intermédio do braço escravo, para a acumulação originária de capital. Conforme os autores:

A articulação produtiva entre o mundo colonial e a economia central europeia, bem como a acumulação de capital proporcionada pelo capital escravista-mercantil mostraram-se altamente relevantes no processo de acumulação do capital, ao mesmo tempo em que suas condições de existência estavam intimamente relacionadas ao desenvolvimento do capitalismo em nível mundial (COSTA; PIRES 2010, p. 7-8).

Restam claros os ecos de Eric Williams em Fernando Novais e, por intermédio dele, em determinados setores da historiografia brasileira. É interessante reparar a marcada influência de uma tentativa de explicar as razões do subdesenvolvimento brasileiro à luz das considerações cepalinas a partir de meados do século passado. Fruto da exploração metropolitana ávida por drenar riquezas coloniais, o Brasil teria sempre se mostrado dependente do setor externo para obter razoáveis condições de desenvolvimento socioeconômico. Nessa esteira, um considerável número de pensadores intentou encontrar no passado colonial brasileiro as explicações de nosso precário desenvolvimento. Servir de base ao enriquecimento europeu por intermédio do direito comercial exclusivo e assentado em mão de obra escrava certamente era uma explicação sedutora, pois, tacitamente, a responsabilidade pelas condições econômicas e sociais do país acabava sendo transferida para o sicário colonizador. 


\section{A contribuição do tráfico e da escravidão para a economia britânica}

Dentre os inúmeros aspectos de Capitalismo e escravidão que rederam calorosas discussões, sem dúvida alguma a questão da efetiva contribuição do ultramar para o enriquecimento britânico anterior à Revolução Industrial ocupa lugar de destaque na historiografia. ${ }^{12}$ Richard Sheridan observou que a montagem do sistema produtivo da região jamaicana - conquistada pelos ingleses junto aos espanhóis em 1655 - teria incorporado capital em várias frentes, quais sejam: junto a habitantes locais espanhóis e a imigrantes provenientes da Inglaterra e do Caribe Oriental; através do comércio com as Antilhas Menores; e, essa sim a principal fonte, por intermédio de mercadores londrinos que haviam encorajado Cromwell a conquistar a região. Nesses termos, o rendimento obtido na praça mercantil jamaicana rumava, necessariamente, em duas direções. Ou bem permanecia em território local, ou bem singrava os mares e aportava em terras inglesas. Malgrado a posição relativamente conciliadora do autor - o ultramar favoreceu a acumulação britânica, mas também o fez frente a uma elite mercantil local -, Sheridan reconhece a primazia inglesa na região. Segundo o autor:

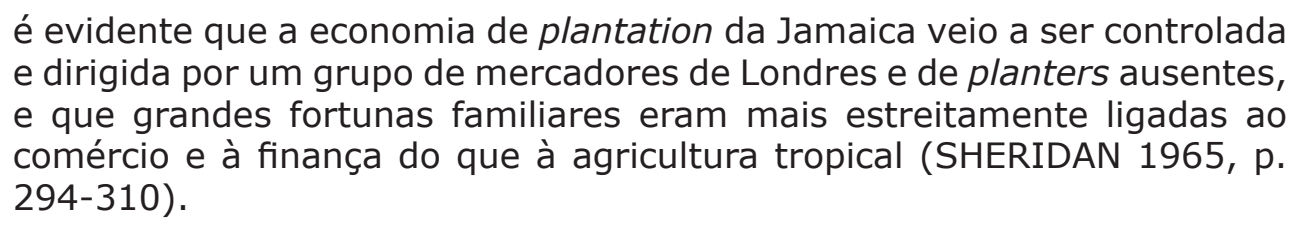

é evidente que a economia de plantation da Jamaica veio a ser controlada e dirigida por um grupo de mercadores de Londres e de planters ausentes, comércio e à finança do que à agricultura tropical (SHERIDAN 1965, p. 294-310).

Três anos após a publicação de Sheridan, Robert Thomas afirmou que seus dados, longe de demonstrarem que as Índias Ocidentais contribuíram para o desenvolvimento da Inglaterra, apontaram, na verdade, para o fato de que tais domínios ultramarinos retardaram esse desenvolvimento. Sheridan se equivocara tanto em sua metodologia de mensuração da riqueza jamaicana, como no aceite do rendimento gerado por essa riqueza. De resto, e aqui reside o problema mais grave, o autor implicitamente teria considerado o extensivo crescimento das colônias de açúcar como a medida de sua contribuição para o desenvolvimento econômico inglês. Consoante Thomas, o único caminho capaz de aferir a suposta ajuda das colônias para o avanço inglês reside em verificar a diferença entre os lucros obtidos pelos investimentos no ultramar - notadamente no Caribe - e os possíveis rendimentos provenientes do emprego desses mesmos recursos em outro setor/lugar (THOMAS 1968, p. 30-31). Richard Sheridan refutou tais críticas apontando não ser possível aventar conclusões com base em uma hipótese impossível de ser testada, uma vez que não há possibilidade de verificar a diferença entre os lucros alcançados no ultramar e os prováveis rendimentos do emprego desses recursos em outra esfera de investimento (SHERIDAN 1968, p. 48).

Paul Bairoch sublinhou a importância de averiguar se os lucros provenientes do comércio ultramarino responderam por uma parte significativa do total dos investimentos realizados na Revolução Industrial. Trabalhando com um cálculo

12 Para uma discussão bastante detalhada do debate em questão cf. BLACKBURN 2003, capítulo XII. 
superestimado, o autor detectou uma participação percentual do capital comercial na formação bruta de capital da ordem de $11 \%$ a $14 \%$. Uma valoração mínima indicaria grandezas de $1,6 \%$ a $2,0 \%$ e a média, mais provável, entre $6 \%$ e $8 \%$. Assim, o autor defendeu a pequena participação do ultramar na formação do capital que financiou a Revolução Industrial. Conforme Bairoch, esse capital proveio de fontes internas da Inglaterra como agricultura, artesanato e comércio local. Ao mercado exterior coube somente o fornecimento de matéria-prima, sendo que de 1790 em diante tal mercado favoreceu consideravelmente a expansão da Revolução Industrial inglesa (BAIROCH 1973, p. 545-548; 570-571).

Patrick O’Brien igualmente se posiciona contrário às ideias de Eric Williams acerca da contribuição do ultramar para a Revolução Industrial. Conforme o autor, entre 1450 e 1750 o comércio centro/periferia ocorreu em escala reduzida, não podendo, de forma alguma, "ser classificado como decisivo para o crescimento econômico da Europa Ocidental". Embora a formação de capital tenha desempenhado um importante papel nesse crescimento nos anos de 1760 até 1850, não pode ser definida como o motor do desenvolvimento econômico britânico, cuja prosperidade proveio, sobremaneira, do progresso tecnológico e da eficiência organizacional. Aliás, mais importante do que o papel do capital nesse processo é determinar qual comércio com a periferia realmente auxiliou no financiamento da acumulação primeira para a Revolução Industrial. Assim, o principal erro dos defensores da importância do ultramar na acumulação primitiva de capitais consiste no fato de eles "não considerarem o papel do comércio [notadamente o ultramarino] em relação à totalidade da atividade econômica", convencendo-se de "que o comércio com a periferia (baseado na exploração, troca desigual e pilhagem) deve ter sido um campo de lucro sem igual da empresa" (O'BRIEN 1982, p. 3-7). Por fim, o autor, sem negar algum nível de contribuição do setor ultramarino para o crescimento econômico europeu, questiona a relevância desse setor no processo com um todo. Em suas palavras:

Europeus sem dúvida investiram uma parte de seus ganhos do comércio com a África, Ásia e as Américas em capital fixo e circulante e, por isso, adicionaram alguma coisa à aceleração da agricultura e à produção industrial doméstica observadas durante o aceleramento da Revolução Industrial. Mas quão importante foi a formação do capital para o crescimento econômico da Europa Ocidental? Os lucros advindos do comércio com a periferia supriram uma porcentagem significativa dos fundos utilizados para financiar os investimentos requeridos pelo crescimento econômico depois de 1750? (O'BRIEN 1982, p. 5, grifos no original).

De certa forma, David Richardson inverteu determinadas propostas de Williams, defendendo que foi a Revolução Industrial que acelerou o comércio triangular, não o inverso. Conforme Richardson, durante o terceiro quarto do século XVIII houve simultaneamente um substancial aumento das atividades do tráfico de escravos britânico, da fabricação de açúcar em suas colônias e das taxas de crescimento da produção industrial. Nesse processo, o tráfico de escravos e a escravidão deveriam ser tomados não como promotores peculiares do desenvolvimento industrial inglês, mas sim como integrantes, embora subordinados, da ampliação da economia 
do Atlântico Norte. Tratar-se-ia de uma expansão ditada por forças internas da sociedade britânica, notadamente o aumento da demanda por produtos coloniais (por exemplo, o açúcar). De fato, essa maior procura pelo produto-rei caribenho viabilizou um incremento das oportunidades de exportação para as mercadorias manufaturadas inglesas nos mercados ultramarinos, de forma a contribuir significativamente para a aceleração nas taxas de crescimento da produção industrial britânica (RICHARDSON 1987, p. 105).

Por fim, David Eltis e Stantey Engerman focaram suas críticas a Capitalismo e escravidão pelo viés do tráfico de escravos. Conforme os autores, o sistema escravista atlântico poderia ter contribuído para o florescimento da economia inglesa de quatro formas: a) oferecendo um mercado para seus produtos manufaturados; b) facultando lucros para financiar a Revolução Industrial em seu alvorecer; c) suprindo as indústrias com matérias-primas baratas; d) aumentado o consumo na Inglaterra com a produção de alimentos por intermédio da mão de obra escrava. Dito de outra forma, além de fornecer matérias-primas mais baratas para setores industriais emergentes, o sistema escravista poderia significar: maiores mercados para os produtos britânicos, lucros para os investidores e incentivos para os consumidores. Porém, "o tráfico atlântico de escravos representou uma pequena parte do comércio atlântico de qualquer potência europeia. Sua contribuição direta para o crescimento econômico de qualquer nação foi trivial". O período composto dos anos de 1798 até 1802 registrou o maior número de escravos embarcados no que tange ao 200 império britânico, momento em que as mudanças estruturais que resultaram na Revolução Industrial já tinham iniciado havia muito tempo. Para os autores, "o tráfico de escravos foi mais importante em termos relativos no terceiro quarto do século XVIII do que no último. Entretanto, em nenhum dos períodos essa atividade pareceu mais relevante quando comparada com outros ramos do comércio de longa distância". Logo, se o tráfico fosse determinante para a Revolução Industrial, ela deveria ter ocorrido antes em Portugal do que na Inglaterra (ELTIS; ENGERMAN 2000, p. 125-130).

Barbara Solow é, seguramente, um dos nomes de maior destaque na defesa da tese de Williams. Para a autora, o argumento segundo o qual a escravidão e o tráfico de escravos favoreceram enormemente o enriquecimento e o crescimento da Inglaterra permanece não afetado pelas críticas a ele direcionadas. Endossa a noção de que o capital aplicado nas Índias Ocidentais britânicas poderia ter sido investido em qualquer outro lugar do império, mas teria facultado uma taxa de retorno menor. A alta taxa proporcionada pelo Caribe era devedora da existência de uma oferta elástica e de uma mão de obra barata, a escrava. Rebatendo as considerações de Engerman, Solow afirmou que suas conclusões não se fiam em suas próprias estatísticas. A incidência dos lucros do tráfico de escravos sobre a formação de capital não teria sido insignificante para o período do início do aceleramento do crescimento britânico. Conforme a autora, "a razão do total dos lucros do tráfico de escravos mais os lucros totais em investimentos das Índias Ocidentais para a formação do capital britânico, contrariamente às estimativas de Engerman, é tão grande que é quase inacreditável" (SOLOW 1985, p. 102-105). 
Para Solow, 37 milhões de libras aplicadas nas Índias Ocidentais originariam um ganho quatro a sete vezes maior do que um investimento da mesma monta na Grã-Bretanha. Assim, os lucros adicionais sobre o capital gerados pelo trabalho escravo no Caribe se revelaram fonte de significativa poupança (aplicada no setor industrial inglês) (SOLOW 1985, p. 111). Em trabalho posterior, a autora novamente voltou à carga na defesa das ideias de Williams, asseverando que a escravidão resultou em grandes lucros para a Europa e para o comércio. Isso em função de ela introduzir suprimento elástico de um gênero produtivo para a economia, possibilitar altas taxas de reservas econômicas e habilitar tais reservas a serem investidas produtivamente. Embora tenha matizado a relação escravidão/Revolução Industrial ao sustentar que a primeira não causou a segunda (mas desempenhou papel importante), Solow sublinhou que tal sistema introduziu uma oferta mais elástica de trabalho no mundo colonial, tornando o investimento consideravelmente produtivo e viabilizando constantes retornos aos proprietários de capital (SOLOW 1987, p. 56-72).

Ainda em âmbito internacional, outros autores foram influenciados pelas ideias de Eric Williams. Franklin Knight, por exemplo, ao discorrer sobre o sistema escravista e o capitalismo arcaico nos impérios espanhol e português entre 1492 e 1713, afirmou que a escravidão ofereceu duas vantagens ao advento do capitalismo. A primeira consiste no fato de os cativos servirem ao propósito produtivo, uma vez que eram mão de obra para produção cuja finalidade repousava em ofertar produtos nos mercados consumidores metropolitanos. Tratando-se de uma força de trabalho não remunerada, a escravidão gerava produtos mais baratos incitando o consumo, proporcionando lucros consideráveis aos produtores e, dessa forma, fomentando as relações mercantis que acabaram originando investimentos industriais. Em um segundo momento, o sistema escravista, tornando os escravos mercadorias, impulsionava sua movimentação de mercado para mercado onde eram vendidos ou trocados facilmente, gerando, por isso, riqueza. Nas palavras do autor, "a escravidão forneceu ligações multifacetadas que promoveram o surgimento do capitalismo". Nesse sentido, o tráfico teria operado em sintonia com outros ramos comerciais, demandando uma variedade de produtos para troca no mercado atlântico. Tanto na África como na América o incremento comercial do tráfico acelerou os mecanismos de produção e de troca (KNIGHT 1991 p. 65-66).

Por seu turno, Joseph Inikori argumenta que o vigor do setor ultramarino nos séculos XVII e XVIII dependeu inteiramente do crescimento do sistema atlântico baseado no comércio escravo e na escravidão africana nas Américas, de modo que esses dois pontos foram cruciais para as transformações capitalistas da Inglaterra. Prescindindo das oportunidades oferecidas pela expansão da escravidão e do tráfico no sistema atlântico, muito provavelmente as principais economias da Europa ocidental decairiam (INIKORI 1987, p. 91-92). Eugene Genovese também atrelou a escravidão à ascensão da sociedade industrial. Conforme o autor, a próspera agricultura do interior escravista do sul dos Estados Unidos serviu de base para o desenvolvimento industrial, provendo um mercado para manufaturas e uma fonte de acumulação de capital. De resto, a riqueza 
dos agricultores dependeu do crescimento de centros industriais para seus produtos. Ao abordar o tema da independência do sul escravista estadunidense da Inglaterra industrial, Genovese não perdeu de vista a importância da escravidão. Conforme o autor:

A sociedade de plantation que começou como um apêndice do capitalismo britânico terminou como uma poderosa e amplamente autônoma civilização com pretensões e possibilidades aristocráticas, ainda que tenha permanecido ligada ao mundo capitalista através de vínculos de produção de commodities. O elemento essencial nessa civilização distinta foram os senhores de escravos (GENOVESE 1989, p. 14-16).

Observa-se que a premissa básica de Williams de que o tráfico de escravos e a escravidão africana concorreram diretamente para o enriquecimento britânico - com o que Fernando Novais está em sintonia - não é um consenso em termos historiográficos. De um lado, põe-se em perspectiva a relevância desses dois fatores no desenvolvimento econômico inglês questionando, inclusive, sua rentabilidade. De outro, esses pontos são tomados como a principal causa do progresso britânico em função não apenas dos lucros que viabilizavam, mas também devido ao fato de fomentarem a produção manufatureira na Inglaterra. Certo é que, ao contrário da historiografia internacional, a historiografia brasileira, acordando que o tráfico era uma atividade extremamente lucrativa, vem negligenciando o debate relativo ao papel da escravidão nas terras americanas de domínio luso no enriquecimento europeu.

\section{O progresso do capitalismo e o fim da escravidão}

Outro aspecto de Capitalismo e escravidão que suscitou um forte debate é o papel desempenhado pelo capitalismo industrial na crise do sistema escravista. De acordo com Eric Williams, no final do século XVII o foco da política econômica britânica migrou da acumulação de metais preciosos para o desenvolvimento industrial, com o aumento de empregos e o encorajamento das exportações. Na lógica de funcionamento mercantilista, o melhor caminho para reduzir custos e, logo, competir com outros países englobava pagar baixos salários, para o que uma população numerosa era fundamental. Dessa forma, a condição básica da colonização - a emigração da metrópole para a colônia - inviabilizaria o projeto econômico britânico. Assim, a Inglaterra, via Companhia Africana Real, voltou-se para o tráfico de escravos no sentido de facultar tanto a colonização em si como os baixos salários necessários ao desenvolvimento econômico inglês. Todavia, quando tal prática levou à maturidade a expansão das forças produtivas metropolitanas, automaticamente tornou-se um freio ao progresso britânico - um freio de difícil remoção. Na medida em que a ascensão industrial avançava a níveis realmente elevados, o sistema operante nas Índias Ocidentais passou a ser duramente atacado no âmbito da escravidão e do monopólio comercial. Advogou-se que tal sistema não era lucrativo, razão mais do que suficiente para destruí-lo. Com o declínio do mercantilismo, a Inglaterra pôde agir contra o tráfico de escravos (proibido 
em 1807) e a escravidão (abolida em 1833). O monopólio do açúcar findou em 1846 (WILLIAMS 1994, p. 15-16; p. 126-136).

Para Fernando Novais, o fim da escravidão surge como condição do avanço do capitalismo. Nas palavras do autor: "a ultrapassagem do último e decisivo passo na instauração da ordem capitalista pressupunha, de um lado, ampla acumulação de capital por parte da camada empresária, e de outro, expansão crescente do mercado consumidor de produtos manufaturados" (NOVAIS 1995, p. 70). Desse modo, em um momento a escravidão serviu à acumulação de capitais, noutro atuou como um entrave para o livre desenvolvimento do sistema capitalista. Acerca do primeiro ponto:

Nas condições históricas em que se processa a colonização da América, a implantação de formas compulsórias de trabalho decorria fundamentalmente da necessária adequação da empresa colonizadora aos mecanismos do Antigo Sistema Colonial, tendente a promover a primitiva acumulação capitalista na economia europeia (NOVAIS 1995, p. 102, grifos no original).

No que respeita ao segundo ponto:

No contexto do sistema colonial e da economia mercantil-escravista, parte do pagamento do fator trabalho no processo produtivo era feito fora do parque produtor (referimo-nos ao pagamento do preço dos escravos aos seus mercadores); a outra parte (ou seja, manutenção do escravo) processava-se através da produção de subsistência, não dando pois lugar a operações mercantis, pelo menos em larga escala. Logo, nenhuma das parcelas em que, na economia colonial, se dividia a remuneração do trabalho se constituía em procura interna, que estimulasse autonomamente o desenvolvimento econômico. Em suma: a economia colonial mercantil escravista tem necessariamente um mercado interno reduzidíssimo (NOVAIS 1995, p. 110, grifos no original).

Prossegue o autor:

O mecanismo fundamental portanto mantém-se. O universo das relações mercantis é função dos senhores e, digamos, agregados. A massa de produtores diretos (escravos) vive fora das relações mercantis, e isso trava a constituição de um mercado interno. No conjunto, tal configuração do mundo colonial responde ao funcionamento do sistema, enquanto as economias centrais se desenvolvem apenas no nível da acumulação primitiva de capitais, e a produção se expande no nível artesanal, ou mesmo manufatureiro. Quando porém essa etapa é ultrapassada, e a mecanização da produção com a Revolução Industrial, potenciando a produtividade de uma forma rápida e intensa, leva a um crescimento da produção capitalista num volume e ritmo que passam a exigir no ultramar mais amplas faixas de consumo, consumo não só de camadas superiores da sociedade, mas agora da sociedade como um todo, o que se torna imprescindível é a generalização das relações mercantis. Então o sistema se compromete, e entra em crise (NOVAIS 1995, p. 112, grifos no original).

Na esteira de Williams, Novais percebe a escravidão ora fomentando o crescimento econômico/acúmulo de capital na Inglaterra, ora amainando o progresso natural do capitalismo inglês. Em ambos os autores, uma vez percebida a então anomalia representada pelo sistema escravista, tratou-se de instigar 
sua supressão. Em termos da historiografia internacional, Dale Tomich notou precisamente o problema com esse tipo de raciocínio. Para o autor, estudar a abolição do tráfico e da escravidão como "produto de uma transição de arcaicas para modernas formas de economia e política" denota uma "oposição hierárquica entre escravidão e capitalismo" e implica em uma "concepção linear de tempo que elimina a complexidade do processo histórico e obscurece aspectos cruciais tanto da escravidão como do desenvolvimento do capitalismo moderno". Frisa que o argumento que opõe escravidão e mudanças tecnológicas cria determinismos em favor de sua incompatibilidade. ${ }^{13} \mathrm{Em}$ essência, tal concepção traz consigo o risco de análises justapostas e teleológicas. De resto, o autor demonstra como as transformações no padrão de consumo dos crescentes centros urbanos europeus fruto da Revolução Industrial aumentou sua demanda por produtos subtropicais e tropicais, sendo o açúcar um dos principais. Esse contexto gerou uma profunda correlação entre o crescimento da escravidão e da produção açucareira cubanas em pleno século XIX. Conforme Tomich: "o mesmo processo que contribuiu para a destruição da escravidão dentro do império britânico resultou na intensificação da produção escrava em outras partes do hemisfério" - incluindo Cuba, Brasil e Estados Unidos - como parte da divisão internacional do trabalho (TOMICH 1991, p. 297-302).

Em 1976, Eugene Genovese e Elizabeth Genovese apontaram a complexidade desse paradoxo do sistema escravista. Discorrendo sobre a noção de que frente a um declínio nas condições históricas de produção os planters

204 naturalmente redirecionariam a mão de obra escrava para a assalariada caso essa última fosse mais lucrativa, os autores sublinharam que dificilmente a classe dos senhores, cuja vida havia sido forjada por relações de (teoricamente) poder absoluto sobre outro ser humano, estaria apta a negar, tranquilamente, os fundamentos de sua existência social e psicológica apenas em resposta a um balanço de ganhos e perdas (GENOVESE; GENOVESE 1976, p. 9).

Mais de dez anos após a publicação desse artigo, Eugene Genovese repisou algumas de suas considerações e aprofundou outras. Segundo o autor, por um lado a região sul dos Estados Unidos necessitava que o regime escravista findasse para poder se industrializar, por outro, os interesses pessoais dos industriais do sul impediam tal término. $O$ antagonismo entre interesse de grupo e interesse individual refletiu o paradoxo de que o domínio rural dos senhores de escravos requereu algum nível de expansão industrial para sustentar sua economia de plantation e seu poder político, mas não podiam suportar (economicamente) ou tolerar (politicamente) uma ampla industrialização (GENOVESE 1989, p. 181).

Observa-se que a derrocada do Antigo Sistema Colonial fruto dos empecilhos legados pela escravidão não necessariamente resiste a uma crítica mais apurada. De passagem, Jorge Pedreira oferta uma explicação alternativa para essa crise. Segundo o autor, o colapso do antigo sistema colonial teve sua origem nos seguintes fatores: a) o cenário político militar, que vinha contribuindo para o 
favorecimento do comércio português, passou, a partir do final do século XVIII, a se mover contra ele, incidindo na suspensão do regime colonial em 1808 (a invasão espanhola ao território luso em 1801 acarretou altos custos para Portugal na assinatura do armistício); b) as guerras napoleônicas, com nova invasão em 1807, culminaram com a abertura dos portos às nações amigas (o que, precisamente, pôs fim ao Antigo Sistema Colonial). Nos anos seguintes, em função do bloqueio britânico e das calamidades da guerra, a economia lusa entrou em crise. Nesse cenário, a produção industrial e a agrícola foram bastante afetadas, paralisando quase completamente o comércio internacional - retomado apenas em 1841 com uma contínua tendência de queda no que tocava ao Brasil (PEDREIRA 2000, p. 839-865).

\section{Conclusão}

O artigo buscou apontar as influências de Capitalismo e escravidão no trabalho de Fernando Novais Portugal e Brasil na crise do Antigo Sistema Colonial. Para tanto, primeiro o texto apresentou, em linhas gerais, as principais ideias de Williams e alguns dos pontos em que a historiografia internacional discorda das mesmas, principalmente acerca de um dos aspectos básico do livro: a contribuição do ultramar para o enriquecimento britânico por meio da escravidão e do tráfico de escravos. Posteriormente, o artigo demonstrou como a proposta de Williams segundo a qual a lógica de funcionamento do comércio triangular somente atingira a máxima eficiência dentro do sistema mercantilista de exclusivo comercial foi aplicada por Novais para entender de que forma esse sistema favoreceu a acumulação primitiva de capital da Revolução Industrial. O artigo também apontou a leitura de Novais acerca da importância que Williams atribuiu especificamente à escravidão no processo de enriquecimento britânico. Nessa matéria, Novais entendeu que a produção colonial orientada para o mercado europeu e para a acumulação primitiva de capital necessariamente demandava mão de obra escrava.

A seguir, o texto realizou o debate de um dos pressupostos centrais presente tanto em Eric Williams como em Fernando Novais: a efetiva contribuição da escravidão e do tráfico de escravos para o enriquecimento inglês. Tal debate se fez necessário na medida em que ambos os autores atribuíram relevo a esses dois pontos no processo em questão. Nesses termos, o artigo demonstrou que não há um consenso acerca desse tema e sublinhou que na historiografia brasileira tal discussão vem sendo negligenciada. ${ }^{14}$ Por fim, o texto abordou o papel do

\footnotetext{
${ }_{14}$ Nas últimas décadas, em geral a historiografia brasileira tratou de estudar a escravidão com vistas à melhor compreensão de sua dinâmica interna, dispensando pouca atenção ao seu papel no processo de enriquecimento de nações estrangeiras. A título de exemplo, vários pesquisadores abordaram os esforços da Coroa portuguesa no recrudescimento dos impostos cobrados na capitania de Minas Gerais. Porém, pouco se falou sobre o fato de terem sido os escravos que concorreram mais diretamente para a extração aurífera. Ou seja, eles contribuíram de uma forma ou de outra para o enriquecimento quer luso, quer inglês (sem contar que a maioria desses cativos ingressou na morada do ouro via tráfico atlântico de escravos, atividade em que vários países tomaram parte). Por outro lado, muito se sabe acerca da dinâmica de funcionamento do sistema escravista em Minas Gerais, do papel desempenhado pelas negras de tabuleiro nessa sociedade, da grande quantidade de alforrias registradas ao longo de todo o século XVIII, do peso dos escravos no sistema de crédito etc. De resto, cumpre registrar que as influências provenientes da micro-história italiana têm orientado muitas pesquisas a observar trajetórias de vida, estratégias de ação, relações sociais etc., perdendo-se de vista a perspectiva macro, espaço privilegiado para o estudo da contribuição da escravidão e do tráfico de escravos no enriquecimento europeu e no engendrar da Revolução Industrial.
} 
capitalismo industrial no fim do sistema escravista. Da mesma forma que Williams, Novais percebeu a escravidão atuando em dois estágios do desenvolvimento capitalista: primeiro concorrendo para facultar tal desenvolvimento, depois se tornando entrave para o mesmo, sendo necessária sua eliminação.

Do posto, faz-se necessário sublinhar que o presente artigo não intenta dar números finais ao debate sobre o Antigo Sistema Colonial. Pelo contrário, seu objetivo consiste exatamente em trazer à baila a importância desse debate ao apontar as influências de Eric Williams em Fernando Novais. Na ocasião em que Capitalismo e escravidão acaba de ser relançado em língua portuguesa, rediscutir a tese sobre o Antigo Sistema Colonial à luz do clássico livro de Williams talvez favoreça o avanço da historiografia própria ao tema. Atualmente, a historiografia relativa à sociedade colonial brasileira cuidou de demonstrar aspectos que à época da escrita da tese de Fernando Novais permaneciam ocultos, ou parcialmente compreendidos, para a maioria dos pesquisadores. A título de exemplo, hoje conhecemos mais detidamente a lógica de funcionamento do mercado interno colonial e das intricadas redes comerciais operantes na bacia atlântica, em geral, e no Império Ultramarino Português, em particular. De igual maneira, os estudos acerca do sistema escravista da América lusa apontaram para o dinamismo das relações perpetradas entre senhores e escravos, para as possibilidades de enriquecimento dos forros etc. Hoje sabemos que parte da riqueza produzida nessa sociedade permaneceu nas mãos não apenas de sua elite econômica, mas também nas mãos de uma variada gama de indivíduos que compunham o tecido

206 social do Brasil Colônia. Nesse sentido, a retomada das discussões sobre a tese de Williams poderiam melhor elucidar a real contribuição da sociedade colonial brasileira não apenas para o enriquecimento dessa ou daquela nação, mas para o desenvolvimento do próprio sistema pré-capitalista na época moderna.

\section{Referências bibliográficas}

ANSTEY, Roger. Capitalism and slavery: a critique, The economic history review, vol. 21, n. 2, 1968, p. 307-320.

ARRUDA, José. Exploração colonial e capital mercantil. In: SZMRECSÁNYI, Tamás (org.). História econômica do período colonial. $2^{a}$ ed. São Paulo: Hucitec, 2002 [1996], p. 217-223.

. O sentido da Colônia: revisitando a crise do antigo sistema colonial no Brasil (1780-1830). In: TENGARRINHA, José (org.). História de Portugal. Bauru: EDUSC; São Paulo: UNESP, 2000, p. 245-263.

BAIROCH, Paul. Commerce international et genèse de la révoltion industrielle anglaise, Annales: économies, sociétés, civilisition. 28 anneè, n. 2, 1973, p. 541-571.

BLACKBURN, Robin. A construção do escravismo no Novo Mundo, 14921800. Rio de Janeiro: Record, 2003.

BECKLES, Hilary. Capitalism, slavery and Caribbean modernity, Callaloo, vol. 20, n. 4, 1997, p. 777-789. 
BURNARD, T. G. 'Prodigious riches': the wealth of Jamaica before the American Revolution, The economic history review, vol. 54, n. 3, 2001, p. 506-524.

CARDOSO, Ciro. As concepções acerca do 'sistema econômico mundial' e do 'antigo sistema colonial': a preocupação obsessiva com a 'extração de excedente'. In: LAPA, José Roberto (org.). Modos de produção e realidade brasileira. Petrópolis: Vozes, 1980, p. 109-132.

Escravo ou camponês? O protocampesinato negro nas Américas. São Paulo: Brasiliense, 2004 [1987].

CARRINGTON, Selwyn. Capitalism and slavery and Caribbean historiography: an evaluation, The journal of African history, vol. 88, n. 3, 2003, p. 304-312.

COSTA, Iraci del Nero; PIRES, Julio Manuel (orgs.). O capital escravistamercantil e a escravidão nas Américas. São Paulo: EDUC; FAPESP, 2010.

ELTIS, David; ENGERMAN, Stanley. The importance of slavery and the slave trade to industrializing Britain, The journal of economic history, vol. 60 , n. 1, 2000, p. 123-144.

FARNIE, D. A. The commercial empire of the Atlantic, 1607-1783, The economic history review, vol. 15, n. 2, 1962, p. 205-218.

FISHER, H. E. S. Anglo-Portuguese trade, 1700-1770, The economic history review, vol. 16, n. 2, 1963, p. 219-233.

FRAGOSO, João. Homens de grossa aventura: acumulação e hierarquia na praça mercantil do Rio de Janeiro, 1790-1830. 2a ed. Rio de Janeiro: Civilização Brasileira, 1998 [ 1992].

FREYRE, Gilberto. Casa-grande e senzala: formação da família brasileira sob o regime da economia patriarcal. 35a ed. Rio de Janeiro: Record, 1999.

GENOVESE, Eugene; GENOVESE, Elizabeth. The slave economies in political perspective, The journal of American history, vol. 66, n. 1, 1976, p. 7-23.

. The political economy of slavery: studies in the economy and society of the slave south. Wesleyan University Press, 1989.

HAMILTON, Earl. American treasure and the rise of capitalism (1500-1700), Economica, n. 27, 1929, p. 338-357.

HENRY, Ralph. Eric Williams and the Reversal of the Unequal Legacy of Capitalism and Slavery, Callaloo, vol. 20, n. 4, 1997, p. 829-848.

INIKORI, Joseph. Africans and the industrial revolution in England: a study in international trade and economic development. Cambridge University Press, 2002.

. Slavery and development of industrial capitalism in England. In: SOLOW, Barbara; ENGERMAN, Stantely (orgs.). British capitalism and caribean slavery. Cambridge University Press, 1987, p. 79-101. 
KNIGHT, Franklin. Slavery and lagging capitalism in the Spanish and Portuguese American empires, 1492-1713. In: SOLOW, Barbara (org.). Slavery and the rise of the atlantic system. Cambridge University Press, 1991, p. 62-74.

NOVAIS, Fernando. Portugal e Brasil na crise do antigo sistema colonial (1777-1808). Ed. 6a. São Paulo: HUCITEC, 1995 [1979].

O'BRIEN, Patrick. European economic development: the contribution of the periphery, The economic history review, vol. 35, n. 1, 1982, p. 1-18.

PEDREIRA, Jorge. From growth to collapse: the breakdown of the old colonial system: Portugal and Brazil (1750-1830), The Hispanic American review, vol. 80 , n. 4, 2000, p. 839-865.

PRICE, Jacob. What did merchant do? Reflections on British overseas trade, 1660-1790, The journal of economic history, vol. 49, n. 2, 1989, p. 267-284.

RICHARDSON, David. The salve trade, sugar, and British economic growth. In: SOLOW, Barbara; ENGERMAN, Stanley (orgs.). British capitalism and Caribbean slavery: the legacy of Eric Williams. Cambridge University Press, 1987, p. 103-133.

SHERIDAN, Richard. Africa and the Caribbean in the Atlantic slave trade, The American historical review, vol. 77, n. 1, 1972, p. 15-35.

. The wealth of Jamaica in the eighteenth century: a rejoinder, The economic history review, vol. 21, n. 1, 1968, p. 46-61.

. The wealth of Jamaica in the eighteenth century, The economic history review, vol. 18, n. 2, 1965, p. 292-311.

SMITH, Adam. Riqueza das nações. São Paulo: Folha de São Paulo, 2010 [ 1776].

SOLOW, Barbara. Capitalism and slavery in the exceedingly long run. In: SOLOW, Barbara; ENGERMAN, Stanley (orgs.). British capitalism and caribbean slavery: the legacy of Eric Williams. Cambridge University Press, 1987, p. 51-77.

Caribbean slavery and British growth: the Eric Williams hypothesis, Journal of development economics, 17, 1985, p. 99-115.

SOLOW, Barbara; ENGERMAN, Stanley (orgs.). British capitalism and Caribbean slavery: the legacy of Eric Williams. Cambridge University Press, 1987, p. 51-77.

THOMAS, Robert. The sugar colonies of the Old Empire: profit or loss for Great Britain?, The economic history review, vol. 21, n. 1, 1968, p. 30-45.

TOMICH, Dale. World slavery and Caribbean capitalism: the Cuban sugar industry, 1760-1868, Theory and society, vol. 20, n. 3, 1991, p. 297-319. 
VILLELA, André Arruda. Exclusivo metropolitano, 'superlucros' e acumulação primitiva na Europa pré-industrial, Topoi, vol. 12, n. 23, jul-dez, 2011, p. 4-29.

WILLIAMS, Eric. Capitalism and slavery. The University of North Carolina Press, 1994 [1944]. 